\title{
The Possible Role of Non-Structural Carbohydrates in the Regulation of Tree Hydraulics
}

\author{
Martina Tomasella ${ }^{1, *(\mathbb{D}}$, Elisa Petrussa ${ }^{2}{ }^{(}$, Francesco Petruzzellis ${ }^{1}\left(\mathbb{D}\right.$, Andrea Nardini ${ }^{1}$ and \\ Valentino Casolo ${ }^{2}$ \\ 1 Department of Life Sciences, University of Trieste, 34127 Trieste, Italy; fpetruzzellis@units.it (F.P.); \\ nardini@units.it (A.N.) \\ 2 Department of Agriculture, Food, Environmental and Animal Sciences, University of Udine, Via delle \\ Scienze 91, 33100 Udine, Italy; elisa.petrussa@uniud.it (E.P.); valentino.casolo@uniud.it (V.C.) \\ * Correspondence: martina.tomasella@units.it; Tel.: +39-040-558-3873
}

Received: 31 October 2019; Accepted: 22 December 2019; Published: 24 December 2019

\begin{abstract}
The xylem is a complex system that includes a network of dead conduits ensuring long-distance water transport in plants. Under ongoing climate changes, xylem embolism is a major and recurrent cause of drought-induced tree mortality. Non-structural carbohydrates (NSC) play key roles in plant responses to drought and frost stress, and several studies putatively suggest their involvement in the regulation of xylem water transport. However, a clear picture on the roles of NSCs in plant hydraulics has not been drawn to date. We summarize the current knowledge on the involvement of NSCs during embolism formation and subsequent hydraulic recovery. Under drought, sugars are generally accumulated in xylem parenchyma and in xylem sap. At drought-relief, xylem functionality is putatively restored in an osmotically driven process involving wood parenchyma, xylem sap and phloem compartments. By analyzing the published data on stem hydraulics and NSC contents under drought/frost stress and subsequent stress relief, we found that embolism build-up positively correlated to stem NSC depletion, and that the magnitude of post-stress hydraulic recovery positively correlated to consumption of soluble sugars. These findings suggest a close relationship between hydraulics and carbohydrate dynamics. We call for more experiments on hydraulic and NSC dynamics in controlled and field conditions.
\end{abstract}

Keywords: NSC; PLC; xylem sap; $\mathrm{pH}$; hydraulic recovery; drought; stem; sugars; starch; embolism

\section{Introduction}

The maintenance of long-distance water transport is an essential requisite for the survival and competitive success of vascular land plants. This is because plants lose large amounts of water through open stomata, parallel to $\mathrm{CO}_{2}$ uptake for photosynthesis. At the same time, plants need to keep tissues hydrated in order to grow and maintain metabolic processes [1].

Under ongoing climate changes apparently leading to increased intensity and frequency of drought events [2], hydraulic failure, i.e., the loss of substantial hydraulic function that induces plant desiccation, is a major and recurrent cause of tree mortality and forest decline worldwide [3]. This is explained by the fact that woody plants are vulnerable to embolism formation and apparently operate close to thresholds for runaway embolism in all biomes, even under 'normal' climate conditions [4]. Even forest biomes not assumed to be water-limited, such as tropical rainforests, have been reported to be more vulnerable to climate change than previously expected and related episodes of tree mortality were attributed to hydraulic deterioration [5].

Stems, branches and coarse roots are responsible for the transport of water from fine roots to the leaves and are also the main non-structural carbohydrate (NSC) storage sites in woody plants [6]. 
In woody tissues, the most abundant NSC specimens, mainly stored in parenchyma cells, are starch (the main insoluble storage compound) and low molecular weight sugars (glucose, fructose and sucrose). In some tree families, oligosaccharides such as stachyose and raffinose (sugars involved in phloem transport together with sucrose), and polyols such as pinitol, are also relevant and abundant $[7,8]$. Lipid stores are also particularly abundant in some genera such as Tilia, Pinus, Picea and Larix [9]. NSC stores play several key roles in plant functioning, but drought may alter the total amount, the allocation and the partitioning of different NSCs [6]. NSC depletion occurs when carbon consumption overcomes carbon assimilation, owing to drought-induced stomatal closure and/or increased respiration rates. Although not ubiquitous like hydraulic failure, carbon starvation has been observed in declining trees [10], and it does frequently occur in combination with hydraulic failure [3]. This underlines that the two mechanisms are not mutually exclusive and suggests possible close relationships between the two phenomena [11-13].

Together with drought resistance, the post-drought functional recovery potential of plant species may be a key driver of ecosystem dynamics under the predicted increase in frequency of drought events [1]. Nevertheless, while functional and physiological mechanisms adopted by plants during drought stress have been quite extensively explored, relatively less attention has been paid to tree recovery [14]. Trees surviving severe drought need to rebuild new organs and tissues, and new functional xylem [15]. Nevertheless, the possible legacy effects of severe droughts on long-lived woody plants include slowing down of growth for one to several years after the drought event, thus lowering the carbon storage capacity of forest ecosystems [16]. In particular, climate change may negatively impact plant growth because enhanced carbon fixation due to increased atmospheric $\left[\mathrm{CO}_{2}\right]$ can possibly be counteracted by a higher increase in respiration rates due to rising temperatures [17]. Moreover, hydraulic acclimation can lead to reduction in growth and production of smaller, less conductive xylem conduits [18]. In addition, there is growing evidence that at least some tree species can recover their hydraulic function in the short term (hours to several days), when xylem water potential rises again close to zero [19]. Either if occurring through cambial growth or via restored conduit functionality, hydraulic recovery putatively implies the use of NSC stores [20]. Therefore, maintaining relatively high NSC levels during drought stress and keeping them available during the recovery phase may be crucial for tree vigor and survival.

In the past couple of decades, an increasing number of studies have focused on the role of NSCs in promoting plant resistance and resilience to drought stress. In fact, NSC-containing parenchyma cells and water-transporting xylem conduits are physically connected and can exchange water and solutes. However, an exhaustive portrait of the mechanistic relevance of NSCs for the hydraulic functioning of woody plants has not been provided yet [21], especially concerning organs with high construction costs such as stems and branches. In addition, a collection of the currently available studies relating stem embolism dynamics with the relative NSC changes is missing. The main goals of this review are (i) to provide a view on the state-of-the-art on the role of NSCs in the maintenance of water transport in woody plants under drought and recovery; and (ii) to identify possible relationships between tree hydraulic and NSC dynamics.

\section{Plant Hydraulics and Drought Stress}

Water absorbed by plant roots is pulled through the xylem up to the evaporative surfaces of leaf mesophyll cell walls in a passive process that does not require metabolic energy [22]. This process is explained by the Cohesion-Tension Theory, which in short indicates that plants generate a transpiration-driven "tension" to pull water and dissolved solutes upwards. The cohesive properties of the hydrogen-bonded water molecules, together with small lumen size and adhesive properties of conduits, allow to sustain large water tensions and, consequently, to avoid the breakage of the water continuum along the xylem pipeline [23,24]. This long-distance water transport occurs through a network of non-living conduits with reinforced cell walls that can mechanically sustain large negative pressures [25]. Xylem conduits are interconnected by pits, i.e., microscopic regions where the conducting 
elements are lacking secondary wall. Therefore, only a middle lamella and two thin primary walls separate adjacent conduits at the pit level. These separations, called pit membranes, are composed by a dense matrix of cellulose microfibrils and other wall components that ensure water and solutes flow but at the same time protect conduits against gas entry [26]. When a conduit becomes gas-filled, pit membranes act as "safety valves" blocking the aspiration of gas bubbles into the adjacent functional water-filled conduits [27]. Given that gas-filled conduits are subjected to positive pressure while the water-filled ones are under tension, a gas phase can be aspirated through the pores of the pit membranes at critical tension values, causing embolism propagation. This limit mainly depends on pit membrane properties such as thickness and porosity in angiosperms, and torus-pit aperture overlap in conifers [26]. Moreover, the expansion of a gas bubble with a certain radius in a xylem conduit at a certain $\Psi_{x}$ (xylem water potential) depends on xylem sap surface tension $(\gamma)$, which in turn depends on its chemistry and temperature [28]. At progressively lower $\Psi_{x}$, more conduits will embolize, causing a reduction in xylem hydraulic conductance (usually quantified as percentage loss of hydraulic conductance, PLC). Embolism can be also caused by freeze-thaw events in winter. Because gases are insoluble in ice, when xylem sap freezes gas bubbles can coalesce and then expand when temperatures rise again and ice thaws, eventually causing the complete blockage of the conduit at rising xylem sap tension [29].

In response to drought stress, several tree species can ontogenetically modify their wood anatomical traits to reduce hydraulic vulnerability. These adjustments include decreased conduit dimensions (diameter and length), increased conduit wall thickness and wood density, and modifications of pit characteristics [25,30,31]. Even long-term hydraulic adjustments to previous year's droughts can occur, as shown in potted saplings [18] and by dendrochronological studies in tropical rainforest trees [32]. On the other hand, prolonged and/or multiple droughts can weaken the resistance to xylem embolism through deterioration of inter-vessel pit membranes, a phenomenon known as "cavitation fatigue" [33]. Even though embolism formation is a purely physical process depending on the xylem structural properties described above, xylem functionality under changing water availability seems to be additionally connected to metabolic processes [34], involving also NSC metabolism.

\section{Stem NSCs Dynamics and the Maintenance of Hydraulic Function under Drought}

Wood is composed not only of xylem conduits (tracheids and vessels), but also of other cell types like ray and axial parenchyma and, for angiosperms, fibres. Parenchyma rays are the connection bridges between phloem and xylem, and allow the exchange of water and solutes between these two long-distance transport systems [35]. Ray parenchyma cells are connected to axial parenchyma cells, forming a 3D network that spreads to the xylem conduits [36]. Parenchyma cells are the primary sites of NSC storage in the sapwood [37]. In accordance with this, a strong positive correlation between wood parenchyma fraction and NSC content was found in young roots and stems of temperate tree species [38]. Fibres provide mechanical support to angiosperm woody stems, but in some species such as Acer and Vitis, the wider ones can also possess living protoplasts that can store and mobilize carbohydrates [39,40]. Among wood parenchyma cells, some of them are highly specialized and commonly referred to as vessel-associated cells (VACs [41,42]; sometimes called 'contact cells' [39]). VACs are in direct contact through pits with the dead conductive xylem conduits and fulfil several functions: water storage (sources of hydraulic capacitance [43]), water transport regulation through aquaporins [42,44], defence (e.g., through production of tyloses and gums [45]), osmoregulation and direct exchange of water, ions and other molecules such as soluble NSCs with the xylem sap $([42,46]$; see Morris et al. [47] for a review). As an example, the export of sugars into the xylem apoplast may be important in winter to avoid or reduce the number of freeze-thaw embolism cycles, because sugars decrease the osmotic potential of xylem sap, thus lowering its freezing point [39,48]. In late winter, branch- and trunk-soluble sugars of Pinus koraiensis positively correlated with PLC and were overall more abundant than in summer [49]. This indicates that sugars mobilization over winter might 
represent a cold hardening strategy [48], but could be also putatively related to the need of maintaining and/or restoring hydraulic function [50,51] (see below).

NSCs are unequivocally involved in promoting plant drought resistance. Sugars, together with sugar alcohols, amino acids and inorganic ions, are accumulated for osmoregulation in living cells, including wood parenchyma and secondary phloem, in order to maintain cell turgor under declining water availability [52]. In fact, tropical tree seedlings enriched in NSCs maintained higher stem water potentials during severe drought and survived longer [53]. Moreover, given the physical continuity between phloem and xylem, insufficient soluble NSC contents in the secondary phloem could result in phloem turgor collapse and subsequent water leakage to the xylem [12,13,54].

Several woody species are known to perform stem photosynthesis in chloroplasts contained in bark, wood and pith. These species could be likely advantaged in the perspective of prolonged or recurrent drought, because stem photosynthesis re-assimilates $\mathrm{CO}_{2}$ released by mitochondrial respiration and by gaseous xylem efflux, thus becoming a local source of carbon under drought stress causing stomatal closure [55,56] and/or absence of leaves [57]. Sugars produced by woody tissue photosynthesis are suggested to play a role in the maintenance of tree hydraulic function under fluctuating water availability $[58,59]$. Moreover, in Populus nigra saplings, stem hydraulic vulnerability increased after prolonged shading of stems, likely reducing the stem NSC pool [60]. Albeit a convincing explanation for this phenomenon is not yet available, the authors suggested that NSCs produced by bark photosynthesis could be the substrate for the production and delivery of lipid surfactants into the xylem sap. Indeed, these molecules have been detected in xylem sap and are proposed to play a role in stabilizing gas nano-bubbles, therefore reducing the risks of embolism formation and propagation [61,62].

Multiple studies conducted in the last decade in different poplar species have demonstrated that severe drought triggers a cascade of metabolic processes in xylem parenchyma cells $[63,64]$. These are supposed to be early events involved in hydraulic restoration when water is again available to the plant $[42,64]$ (see the following section). These events, for which we provide the sequence and related experimental proof below, apparently culminate in the accumulation of low molecular weight sugars in the xylem apoplast (Figure 1a).

Embolism formation is suggested to be sensed by the plant [65] and to act as a trigger for the activation of molecular signals connected to carbohydrate metabolism [42,65]. During the progression of drought and embolism formation, starch content in wood parenchyma cells was often reported to decrease $[18,19,66,67]$. This was associated with a contemporary increase of stem sucrose content $[19,65,67]$ and with regulation of enzymes involved in starch synthesis and degradation, respectively [67]. Accordingly, the same pattern for starch and sucrose content was observed during winter embolism formation in Juglans regia [44] and embolism accumulation strongly correlated with starch depletion and with soluble sugars content in a conifer [49] and in an angiosperm [18].

Sucrose in wood parenchyma could originate from local starch hydrolysis as well as from phloem export. In xylem parenchyma of Populus tremula $x$ alba, glucose, fructose and maltose derived from starch hydrolysis, while sucrose derived from long distance transport through the phloem-to-parenchyma rays pathway. All these sugars accumulated in the xylem apoplast and sap during drought, possibly due to the activation of plasma membrane sugar transporters in VACs [64]. In fact, sugar (especially maltose and sucrose) symporter genes were overexpressed parallel to starch degradation [64], likely sustaining the efflux of disaccharides to the cell walls in contact with xylem conduits. This was accompanied by a decrease in xylem sap $\mathrm{pH}[64,68]$, suggesting the involvement of sucrose-proton co-transporters. Indeed, acidification of xylem sap has been documented in several tree species during dry or prolonged frost periods $[69,70]$. A more acidic sap environment was then associated with an increase in acidic invertases activity, that would break the exported sucrose into glucose and fructose, which have been found in high concentrations in xylem sap of drought stressed plants [71]. Prior to this study, gene expression analyses showed up-regulation of ion transport, aquaporins and sugar metabolism in Populus trichocarpa [68,72], and similar patterns in carbon metabolism and aquaporin expression 
were found in grapevine petioles [73]. Some PIP1 and PIP2 aquaporin genes were overexpressed in parenchyma cells during drought $[74,75]$, also in combination with changes in expression of genes related to sugar metabolism and transport [19]. Abscisic acid (ABA), which plays an important role in signaling drought and coordinating drought responses, is known to be involved in the regulation of stomatal conductance during physiological drought. Additionally, ABA is putatively suggested to affect carbohydrate partitioning by increasing the activity of $\beta$-amylases and invertases during drought not only in leaves [76], but also in stem wood, where a strong positive correlation between ABA content and hexoses has been found for Populus nigra [77].

\section{(a) Drought}

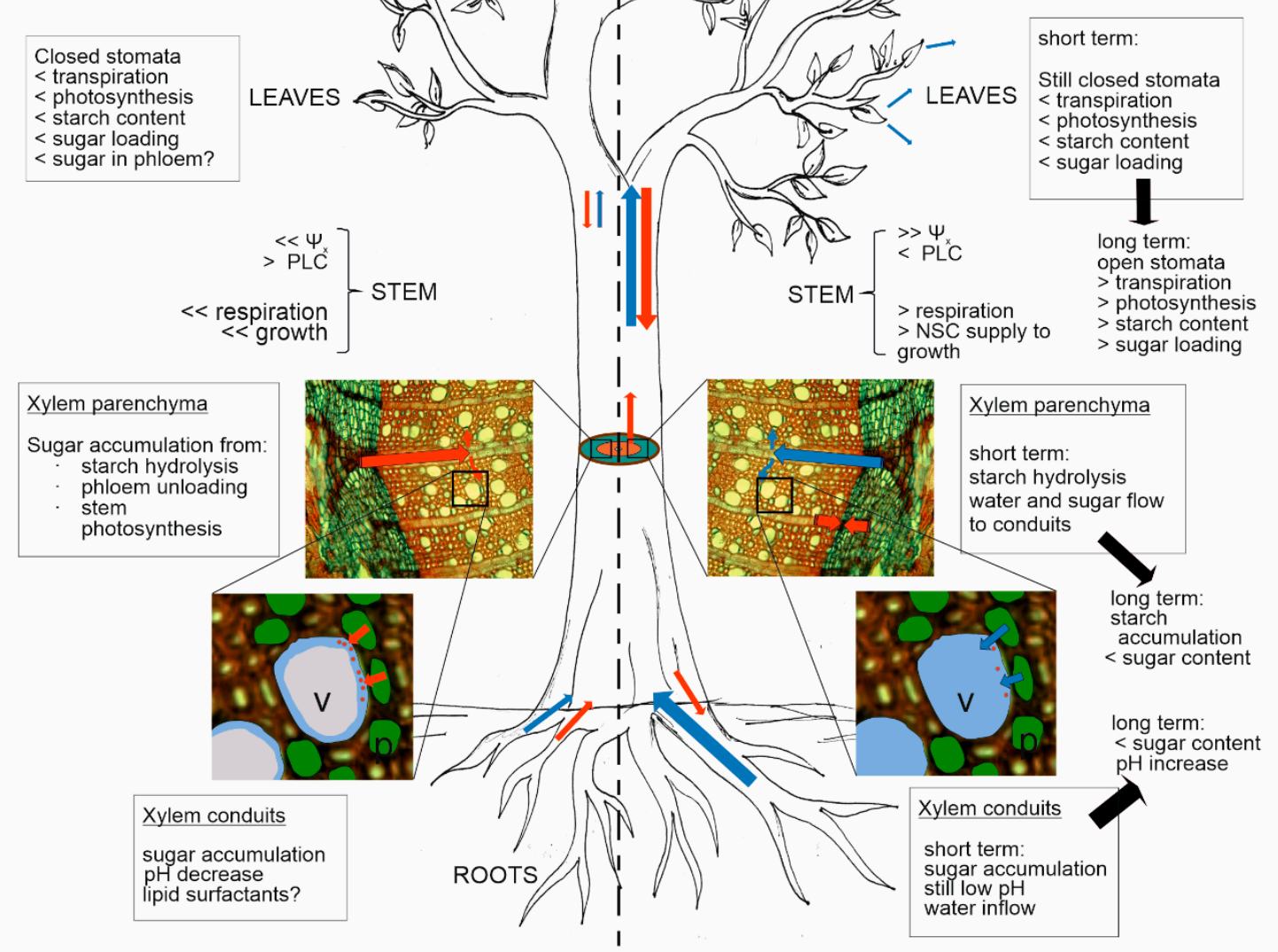

Figure 1. Schematic representation of putative roles of stem NSCs in the hydraulic regulation in woody plants. (a) During drought, root-to-leaf water transport is reduced and NSC reserves (manly from roots ad stems) are mobilized. Stomata are closed and photosynthesis is reduced, and hence sugar export from leaves and transport through phloem is limited. Decreased xylem water potential $\left(\Psi_{\mathrm{x}}\right)$ induces embolism formation in xylem conduits and translocation of sugars to embolized vessels, putatively involving NSC metabolism in stem parenchyma cells and phloem unloading. (b) In the post-drought phase, restored water availability in the soil induces an increase in $\Psi_{\mathrm{X}}$ and a cascade of events leading to the refilling of previously embolized vessels. In the short term upon rehydration, stomata are still closed, transpiration is limited, sugars would still be loaded to the refilling vessels, and water would start to move in the direction of the refilling vessels, washing away the sugars accumulated in xylem sap. In the long term, stomata open and "normal" NSC metabolism and water relations are reestablished, and NSCs are invested for reactivation of cambial growth. Blue and red arrows indicate the direction of water and sugar fluxes, respectively, and their size indicates their magnitude. Question marks indicate putative processes. $v=$ xylem vessel; $p=$ wood parenchyma cells. $<$ indicates low and $>$ indicates high. 


\section{Stem NSCs and the Post-Drought Recovery of Xylem Function}

The recovery of hydraulic function following sub-lethal drought might represent a critical adaptive trait for long-lived trees facing recurrent and/or extreme drought spells [14]. A mid-to-long term strategy for hydraulic recovery is represented by the growth of new xylem by cambial activity, which requires the use of local or imported NSCs $[15,18,78]$. Moreover, during xylem development, an increasing demand of sugars (glucose, fructose and phosphate-sugars) for sustaining secondary wall formation [79] is fulfilled by phloem unloading into parenchyma rays and subsequent sugar movement via apoplastic and symplastic pathways [80].

Short-term mechanisms of xylem hydraulic restoration may act as a "first aid" strategy adopted by plants to partially restore water transport, enabling rehydration of shoots and increasing stomatal conductance. Those mechanisms include positive root pressure, stem pressure, water uptake through leaves and/or bark, and recovery under low residual xylem tension (namely refilling).

Positive root pressures typically generate at night or in early spring, when transpiration is almost entirely suppressed, and require fully saturated soil [81]. This phenomenon is commonly observed in herbaceous plants and arboreal monocots [82] but can also occur in adult temperate woody angiosperms before spring flush $[78,83-86]$. However, a dual mechanism including both generation of root pressure and stem osmotic pressure gradients was demonstrated in Betula pendula [87]. Sauter et al. [39] already observed starch depletion and an increase in sucrose concentration in the xylem sap, together with increased acid phosphatases and respiratory enzymes activity in "contact cells" (i.e., VACs) of Acer saccharum before spring flush. The authors hypothesised a metabolically active process involved in the restoration of sap flow in late winter [39]. Accordingly, in J. regia the positive xylem pressure associated with refilling in late winter/early spring was associated with high sugar concentrations in the xylem sap, indicating an osmotically driven process [88].

Evidence for vessel refilling under moderately negative xylem pressure has been provided in several plant species $[8,19,40,67,85]$. According to the existing model for refilling, VACs would be involved in the restoration of conduit functionality by generating an osmotic driving force and supplying water for refilling [20,42]. In this process, once water is available at recovery, the osmotic gradient generated by the accumulation of solutes in the xylem apoplast during drought reclaims water preferentially from VACs into the gas-filled vessels in an aquaporin-mediated process [20]. This fits with the in-vivo visualization of water droplets appearing and expanding in air-filled vessels in proximity of xylem parenchyma cells in grapevine $[40,89,90]$. Afterwards, once the vessels are refilled, ions and sugars in the xylem sap should be removed through the restored water flow [71].

This mechanistic model involves soluble NSCs in xylem sap as osmoticum for hydraulic recovery, but their possible additional roles are still not well understood. Sugar compounds located in xylem sap are transported even at long distances from the point of secretion into the apoplast and, especially when photosynthesis is reduced (e.g., in early spring before bud break), they can be accumulated and allocated via the transpiration stream to the leaves [91]. This could be an important carbon source during drought, but also upon rehydration when the leaf photosynthetic carbon fixation is low because stomata are still closed and/or photosynthesis is temporarily inhibited. In fact, the daily amount of sugars transported through the xylem from roots to shoots can exceed the daily amount of photosynthetically fixed $\mathrm{CO}_{2}$ under certain environmental conditions [91].

Hydraulic recovery is an energy-requiring process. Plasma membrane $\mathrm{H}^{+}$-ATPase, which in spring were shown to have a high activity in VACs with respect to more distant parenchyma cells [92], could energize the sugar-proton co-transporters during drought and recovery. This could be supported by increased stem respiration, that has been observed in trees after re-irrigation [93]. Moreover, fusicoccin (an activator of $\mathrm{H}^{+}$-ATPase) and orthovanadate (an inhibitor of plasma $\mathrm{K}^{+}$- and $\mathrm{H}^{+}$-ATPase) applied in the stem enhanced and inhibited, respectively, xylem hydraulic recovery [41].

Together with the above-mentioned sugar transporters, $\mathrm{H}^{+}$-ATPase of VACs is involved in the acidification of xylem sap [92]. In Picea abies growing at the timberline, the spring recovery of embolism was associated to a drop in $\mathrm{pH}$ from 7.0 to 5.5 [94], and to an increase in xylem sap surface tension 
$(\gamma)$ from 50 to $67 \mathrm{mN} \mathrm{m}^{-1}$, that in turn increased the resistance to embolism [70]. According to a physicochemical study, the increase in mono- and disaccharides concentration observed during stress in xylem sap (e.g., [64]), cannot alone be responsible for such a large increase in $\gamma$ [95]. Moreover, a decrease in $\mathrm{pH}$ from 8 to 4.5 of a $10 \mathrm{mM} \mathrm{KBr}$ solution (similar $\left[\mathrm{K}^{+}\right]$of xylem sap), increases its $\gamma$ by only about $2 \mathrm{mN} \mathrm{m}^{-1}$ (from 72 to $74 \mathrm{mN} \mathrm{m}^{-1}$ [96]). A decrease in $\gamma$ in xylem sap is supposed to be induced by the presence of surfactants $[70,97]$. However, investigations of xylem sap composition and chemistry in relation to variations in $\gamma$ in field studies are scarce [98] and should deserve more attention, also in relation to changes in non-surface active (inorganic ions, sugars, alcohols) and surface-active (surfactants) compound concentration in xylem sap during drought and recovery.

Given its connectivity with xylem tissue, phloem has been also suggested to be involved in the refilling process $[41,65,98,99]$. In accordance, phloem inactivation via partial or full girdling prevented starch hydrolysis in parenchyma rays [100] and reduced or inhibited refilling [42,67,100-103]. Xylary chloroplasts, locally furnishing sugars, are also thought to play a role in the refilling process $[58,59,101]$.

Refilling can occur within few minutes to hours [85], but it may take longer in dependence on the severity of drought [64]. Indeed, after being exposed to severe drought inducing high PLCs, several woody species recover water potentials within hours after re-irrigation, while the recovery of gas exchange [102] and eventual hydraulic restoration can require days $[63,64,103]$. Hydraulic recovery may occur to a less extent or not occur at all, in dependence on the species and magnitude of drought stress and hydraulic damage. For example, the magnitude of hydraulic recovery in Salix matsudana branches soaked for 6 hours was lower in samples dehydrated to $\Psi_{x}$ of $-2.2 \mathrm{MPa}$ than in those reaching $-1.5 \mathrm{MPa}$ and $-1.9 \mathrm{MPa}$ [101]. In a similar way, stems of Fagus sylvatica saplings reaching PLCs close to thresholds for hydraulic failure (85\%) did not recover hydraulic function in the short term [18].

The reliability of sample preparation methods for destructive hydraulic conductivity measurements has been the centre of a recent debate [104-106], casting doubt on the occurrence of embolism repair under tension [107]. In the past two decades, magnetic resonance imaging (MRI) and X-ray micro tomography (micro-CT) have been used to detect in vivo embolism formation and repair and, possibly, to solve those debates. Some in vivo studies showed the occurrence of refilling under negative pressure (in Vitis spp. [40,89,90,108,109]; in Acer rubrum [110]), while others did not [111-113]. The advantage of these methods over destructive ones is the putative absence of artefacts induced by cutting stem/branch samples. However, the use of X-ray micro-CT can cause cellular damage and alter membrane stability [114], thus possibly inhibiting the refilling process. Clearly, additional efforts are needed to converge on non-controversial protocols and methods for in vivo detection of embolism repair under tension.

Several studies, mainly conducted in gymnosperms, demonstrated that branches can absorb water through leaves and/or bark to refill embolised conduits [50,101,115-117]. In late winter and early spring, when soil water was still frozen, branch hydraulic recovery in P. abies was associated to water absorption from melting snow and to a peak in PIP aquaporin abundance in needle endodermis and phloem [50]. Similar to angiosperms recovering from drought, refilling though needle water uptake in Picea glauca was favoured by aquaporins located in VACs [115] and Liu et al. [101] have recently shown that sugars produced by corticular photosynthesis enhanced water absorption in the bark of soaked branches and promoted xylem refilling.

At present, only a few studies have measured the sugar concentration dynamics in xylem sap during hydraulic recovery. In S. matsudana branches, an increase in ion and soluble sugar content was observed upon stem soaking that preceded refilling via bark water uptake [118]. Similarly, in Populus tremula $\times$ alba, sugars that increased in concentration in xylem sap at the peak of drought, later decreased to unstressed levels upon recovery of hydraulic function [64]. All these studies support the idea that refilling could be driven by an osmotic gradient, probably generated by sugar accumulation in xylem sap. 


\section{NSC-PLC Relationships: A Survey from Currently Available Data}

Relatively few studies, mainly limited to potted plants grown under controlled conditions or cut branches, have investigated the possible mechanistic roles of NSCs in the maintenance and recovery of xylem hydraulics. To highlight eventual recurrent patterns in PLC-NSC dynamics under embolism formation and recovery, we analysed the output of experiments reported in the literature that included quantitative data on stem NSC content and PLC at the end of the stress and after stress relief. Literature search terms included "PLC", "embolism", "non-structural carbohydrate", "NSC", "recovery", "drought" and we selected only studies and plant species for which a significant increase in PLC during stress with respect to control plants or to pre-stress conditions was detected (Table 1). We obtained a list of 25 species, among which 23 were angiosperms and only two were conifers (a tree, P. abies, and a shrub, Pinus mugo). Out of 13 studies, 6 (including 9 species) were performed in controlled potted conditions, two (including 13 species) analysed cut branches which were rehydrated by soaking them in water, and 5 ( 5 species) were conducted in the field. The PLC increase was caused by drought or winter frost (causing freeze-thaw cycles and soil frost), or induced by sample dehydration in the laboratory. Moreover, the analysed studies and species substantially differed in the PLC reached at the end of the stress event (range from $20 \%$ to $85 \%$ ), as well as in the duration of stress exposure (from few hours for dehydrated branches, to months in case of trees in the field) and recovery (from $1 \mathrm{~h}$ to several months). In 7 out of 32 treatment groups included in the analysis (some experiments included more treatment groups within a species $[103,119]$ ), hydraulic recovery was not observed (see Table 1). Also regarding NSCs, the available data were heterogeneous: in some studies only starch was measured, in others the NSCs derived from the bulk stem tissue were measured, while in others bark and wood were separated, and in only three studies (and species) NSC analyses were performed in both bark and wood. Moreover, only two experiments included measurements of xylem sap NSC content, which could not therefore be considered in the analysis.

Statistical analyses were performed with R software (R Core Team, 2017). Correlations between NSC and PLC were tested using Pearson's and Spearman's correlation tests $(\alpha=0.05)$ for normally and non-normally distributed variables, respectively. For some correlations, stem PLC and/or NSC content were not available and, therefore, were not included in the analyses (parameters and data for analyses are reported in the Supplementary Materials; average values of parameters for each study were used). The results of the analyses are presented in Appendix A as Table A1 (correlations during the drought phase) and Table A2 (correlations during the recovery phase).

Our analysis revealed significant correlations between stem hydraulics and NSCs during the drought/frost stress phase. In particular, PLC at the end of the stress ( $\left.\mathrm{PLC}_{\text {end }}\right)$ negatively correlated with starch and total NSC concentration difference between drought/frost-stressed and non-stressed control trees $\left(\Delta \mathrm{Starch}_{\text {end }}\right.$ and $\Delta \mathrm{TotNSC}_{\text {end, }}$, respectively, Figure 2a,c). In almost all the analysed studies, NSCs were depleted during drought (i.e., $\Delta \mathrm{Starch}_{\mathrm{end}}$ and $\Delta \mathrm{TotNSC}_{\mathrm{end}}$ were negative) and this drop was particularly marked for plants with PLCs above $70-80 \%$. Moreover, negative correlations were found between the PLC increase observed during drought $\left(\triangle \mathrm{PLC}_{\mathrm{end}}\right)$ and both the fraction of total NSC at the end of drought/frost stress with respect to non-stressed trees $\left(\operatorname{TotNSC}_{\text {end }} / \operatorname{TotNSC}_{c}\right.$ ), and the soluble

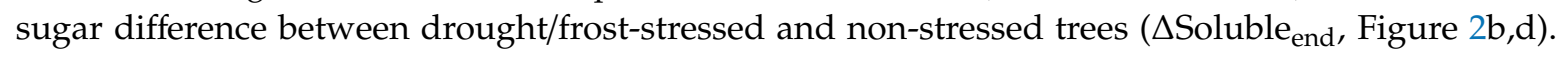
All these correlations support the hypothesis that hydraulic and NSC dynamics under stress conditions are interdependent [49], and that hydraulic deterioration is generally, albeit not always, accompanied by NSC depletion $[3,10]$. 
Table 1. List of studies investigating embolism and non-structural carbohydrate dynamics under drought/frost and post-drought/frost recovery.

\begin{tabular}{|c|c|c|c|c|c|c|c|c|c|}
\hline Species & $\begin{array}{l}\text { Type of } \\
\text { Sample }\end{array}$ & $\begin{array}{l}\text { Embolism } \\
\text { Induction }\end{array}$ & $\begin{array}{l}\text { Rehydration } \\
\text { Type }\end{array}$ & $\begin{array}{l}\text { PLC before } \\
\text { Recovery }\end{array}$ & NSC at Peak Embolism & NSC at Drought Relief & $\begin{array}{l}\text { Recovery } \\
\text { Duration }\end{array}$ & $\begin{array}{l}\text { Hydraulic } \\
\text { Recovery }\end{array}$ & Citation \\
\hline Fagus sylvatica & Pot & SD & SR & $85 \%$ & St decrease, SS increase in W and B & St increase, $S S$ decrease in $W$ and $B$ & One week & No & [18] \\
\hline \multirow{2}{*}{ Fraxinus ornus } & \multirow{2}{*}{ Pot } & \multirow{2}{*}{ SD } & \multirow{2}{*}{ SR } & $76 \%$ & SS and Tot depleted only in B & Not changed & \multirow{2}{*}{ One day } & Yes & \multirow{2}{*}{ [119] } \\
\hline & & & & $78 \%$ & St and Tot depleted in B and W & Not changed & & No & \\
\hline Hibiscus glaber & \multirow{2}{*}{ Field } & \multirow{2}{*}{ SD } & \multirow{2}{*}{ SR } & $70 \%$ & $S S$ increase and $S t$ decrease & $S S$ decrease and $S t$ increase & One week & Yes & \multirow{2}{*}{ [93] } \\
\hline Ligustrum micranthum & & & & $40 \%$ & $S S$ increase and $S t$ decrease & Not changed & One week & Yes & \\
\hline Populus tremula $x$ alba & Pot & SD & SR & $80 \%$ & $\begin{array}{l}\text { SS increase in xylem sap } \\
\text { St decrease, Glu increase in W }\end{array}$ & $\begin{array}{l}\text { SS decrease in xylem sap } \\
\text { Glu decrease in W }\end{array}$ & One week & Yes & [64] \\
\hline \multirow{3}{*}{ Laurus nobilis } & \multirow{3}{*}{ Pot } & \multirow{3}{*}{ SD } & \multirow{3}{*}{ SR } & $23 \%$ & Not changed & Not changed & One day & Yes & \multirow{3}{*}{ [103] } \\
\hline & & & & \multirow{2}{*}{$34 \%$} & \multirow{2}{*}{ Not changed } & \multirow{2}{*}{ Not changed } & One day & Yes & \\
\hline & & & & & & & One week & Yes & \\
\hline Arbutus unedo & \multirow{12}{*}{ СВ } & \multirow{12}{*}{$\mathrm{BD}$} & \multirow{12}{*}{$\mathrm{B} / \mathrm{L} W \mathrm{U}$} & \multirow{12}{*}{$\sim 50 \%$} & \multirow{12}{*}{ N.A. } & St and SS decrease & \multirow{12}{*}{ One hour } & Yes & \multirow{12}{*}{ [120] } \\
\hline Ceratonia siliqua & & & & & & St increase, $S S$ decrease & & Yes & \\
\hline Cercis siliquastrum & & & & & & St and $S S$ decrease & & Yes & \\
\hline Eucalyptus camaldulensis & & & & & & St increase, $S S$ decrease & & No & \\
\hline Laurus nobilis & & & & & & St increase, $S S$ decrease & & Yes & \\
\hline Morus alba & & & & & & St increase, $S S$ decrease & & Yes & \\
\hline Myrtus communis & & & & & & St increase, $S S$ decrease & & Yes & \\
\hline Nerium oleander & & & & & & St decrease, $S S$ increase & & No & \\
\hline Olea europea & & & & & & St and SS decrease & & Yes & \\
\hline Phillyrea latifolia & & & & & & St and SS increase & & No & \\
\hline Pistacia lentiscus & & & & & & St and SS increase & & No & \\
\hline Quercus ilex & & & & & & St and SS not changed & & Yes & \\
\hline Salix matsudana & СВ & $\mathrm{BD}$ & $\mathrm{B} / \mathrm{L} W \mathrm{U}$ & NA & N.A. & $S S$ increase, St decrease in B and $\mathrm{W}$ & 6 hours & Yes & [101] \\
\hline Quercus pubescens & \multirow{4}{*}{ Pot } & SD & SR & $73 \%$ & $\begin{array}{l}\text { Increase in } S S \\
\text { St not changed }\end{array}$ & N.A. & \multirow{4}{*}{5 days } & Yes & \multirow{4}{*}{ [121] } \\
\hline Prunus mahleb & & SD & SR & $30 \%$ & $\begin{array}{l}S S \text { not changed } \\
\text { Increase in } S t\end{array}$ & N.A. & & No & \\
\hline Robinia pseudoacacia & & SD & SR & $68 \%$ & Decrease in $S t$ and $S S$ & N.A. & & No & \\
\hline Ailanthus altissima & & SD & SR & $62 \%$ & Decrease in $S t$ and $S S$ & N.A. & & Yes & \\
\hline $\begin{array}{l}\text { Malus domestica var. } \\
\text { Golden delicious }\end{array}$ & Field & $\mathrm{FT}+\mathrm{FD}$ & SR & $70 \%$ & St not changed in $\mathrm{W}$ and $\mathrm{B}$ & $\begin{array}{l}\text { St decrease in } \mathrm{W} \text { and } \mathrm{B} \text {, more } \\
\text { pronounced in } \mathrm{W}\end{array}$ & $\begin{array}{l}1 \text { to } 3 \\
\text { months }\end{array}$ & Yes & [122] \\
\hline
\end{tabular}


Table 1. Cont.

\begin{tabular}{|c|c|c|c|c|c|c|c|c|c|}
\hline $\begin{array}{l}\text { Malus domestica } \\
\text { (4 cultivars) }\end{array}$ & Field & $\mathrm{FT}+\mathrm{FD}$ & SR & $20-80 \%$ & N.A. & St increase in $\mathrm{W}$ and $\mathrm{B}$ & $\begin{array}{c}\text { Several } \\
\text { weeks }\end{array}$ & Yes & [123] \\
\hline \multirow[t]{2}{*}{ Picea abies } & \multirow[t]{2}{*}{ Field } & $\mathrm{FT}+\mathrm{FD}$ & $\mathrm{B} / \mathrm{L} W \mathrm{U}$ & $43 \%$ & $\begin{array}{l}\text { SS not changed } \\
\text { Very low, constant } S t \text { in } \mathrm{W} \text { and B }\end{array}$ & $\begin{array}{c}\text { St increase in phloem and needles } \\
\text { SS not changed } \\
\text { Very low } S t \text { in } \mathrm{W}\end{array}$ & 1 month & Yes & \multirow[t]{2}{*}[50]{} \\
\hline & & SD & SR & $30 \%$ & St increase in phloem & St decrease in phloem & 3 months & Yes & \\
\hline Picea abies & Pot & SD & SR & $20 \%$ & $\begin{array}{c}\text { St depletion in B } \\
\text { Tot not changed in B and W }\end{array}$ & $30 \%$ depletion of Tot in W & One week & Yes & [8] \\
\hline Pinus mugo & Field & $\mathrm{FT}+\mathrm{FD}$ & $\mathrm{B} / \mathrm{L} W \mathrm{U}$ & $40 \%$ & St and $S S$ not changed & $\begin{array}{c}\text { St increase only in phloem and } \\
\text { needles } \\
\text { SS not changed }\end{array}$ & One month & Yes & [124] \\
\hline
\end{tabular}

Pot = pot experiment; Field = field experiment; $\mathrm{CB}$ = cut branches; $\mathrm{SD}$ = soil drought; $\mathrm{FT}$ = freeze-thaw; $\mathrm{FD}$ = frost drought; $\mathrm{BD}=$ bench dehydration; $\mathrm{B} / \mathrm{L}$ WU = bark/leaf water uptake; SR, soil rehydration; $S t=$ starch; $S S=$ soluble sugars; $G l u=$ glucose; Tot = total NSC; B = bark; W = wood; BT = bulk tissue; N.A. = not available data. 

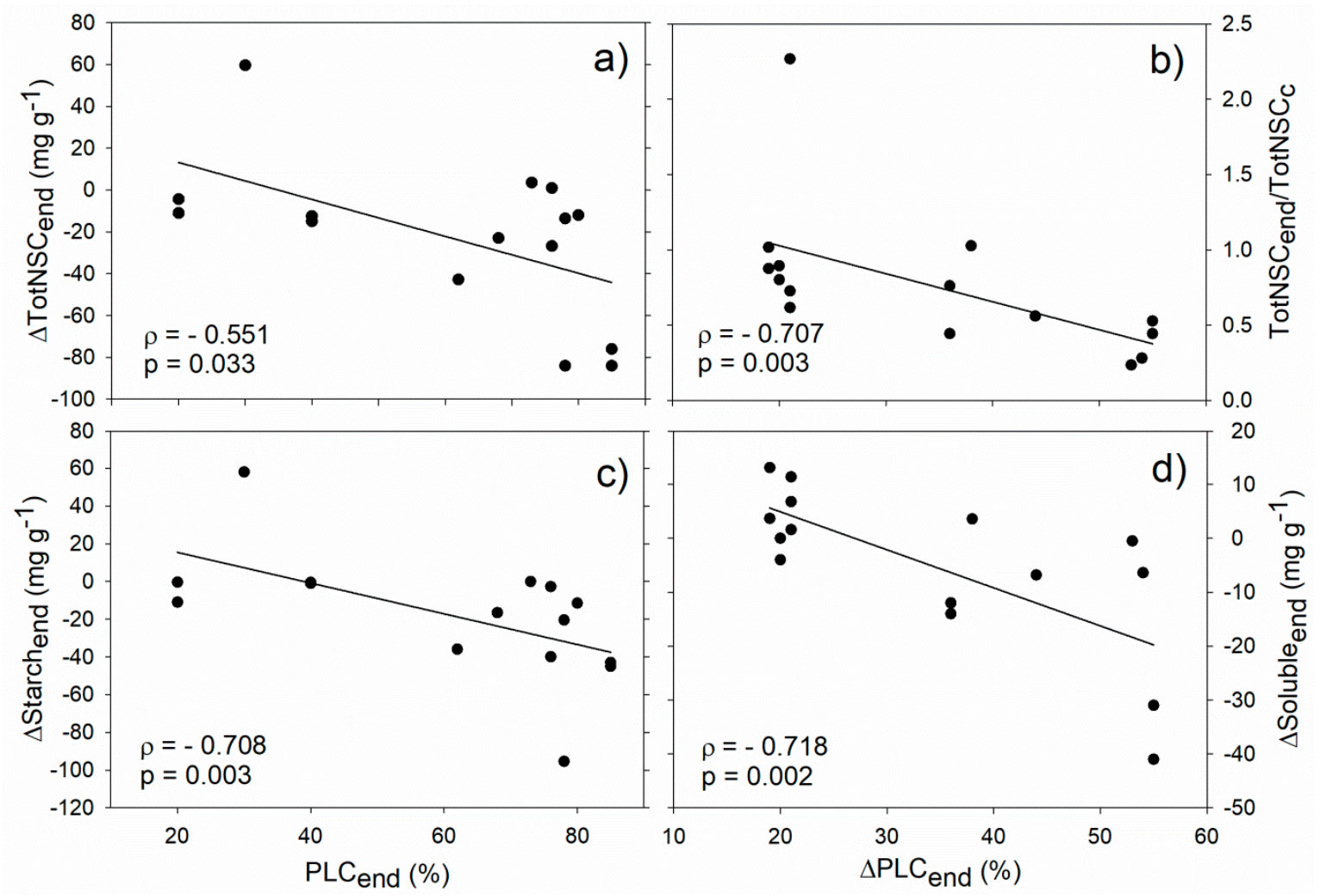

Figure 2. Relationships between stem hydraulics and non-structural carbohydrate (NSC) during drought/frost stress. Correlation between PLC at the end of stress $\left(\mathrm{PLC}_{\mathrm{end}}\right)$ and total NSC concentration $\left(\mathbf{a}, \Delta \operatorname{TotNSC}_{\text {end }}\right)$ and $\operatorname{starch}\left(\mathbf{c}, \Delta \mathrm{Starch}_{\mathrm{end}}\right)$ difference between drought/winter-stressed and non-stressed trees. Correlation between drought/frost-induced PLC increase $\left(\triangle \mathrm{PLC}_{\mathrm{end}}\right)$ and the fraction of total NSC at the end of drought/winter stress with respect to control plants ( $b$, TotNSC end $_{\text {TotNSC }}$ ), and the soluble sugar difference between drought/winter-stressed and non-stressed trees $\left(\mathbf{d}, \Delta\right.$ Soluble $\left._{\text {end }}\right)$. Spearman's correlation coefficient $(\rho)$, related p-value and regression lines are reported.

When looking at the hydraulic recovery phase, a negative correlation emerged between the recovered PLC (i.e., the PLC accumulated during stress that has been recovered upon stress relief, expressed in percentage, $\mathrm{PLC}_{\text {rec_}} \%$ ) and the variation in soluble sugar content after recovery with respect to the end of the stress ( $\Delta$ Soluble $_{\text {rec }} ; \rho=-0.40 ; p<0.05$; Figure 3). In other words, hydraulic recovery positively correlates with the depletion of soluble NSCs during rehydration, and this confirms at a more general scale the pattern reported in a recent study conducted in 12 different angiosperm species [120], that was indeed included in the dataset. Moreover, this would be in agreement with the fact that the magnitude of hydraulic recovery in saplings of four angiosperm species depended on the available sugars at the end of drought [121].

These patterns suggest that the magnitude of hydraulic recovery could depend on the amount of soluble sugars available. As indicated in the previous chapter, the available sugars would play a pivotal role in the recovery because they would be demanded as a substrate for stem respiration [92], as osmotica for embolism repair and for building new xylem tissue. This finding would be also in agreement with the hypothesis that sugars are released into the vessels and subsequently removed when xylem sap flow is restored [42].

Until now, only a few studies have investigated within a species the importance of NSCs in the restoration of hydraulic function upon drought stress relief, by manipulating stem NSC content [103,119]. In one of these, in particular, it was shown that Fraxinus ornus plants with depleted stem wood NSCs at the end of a drought stress did not recover xylem hydraulics at re-irrigation, while those which maintained high NSC concentrations were able to do so [119]. This finding provides evidence in favour of the involvement of NSCs in tree hydraulic regulation and highlights that applying NSC 
manipulation in future studies could possibly provide evidence in favour or against the proposed hypotheses related to hydraulic recovery processes.

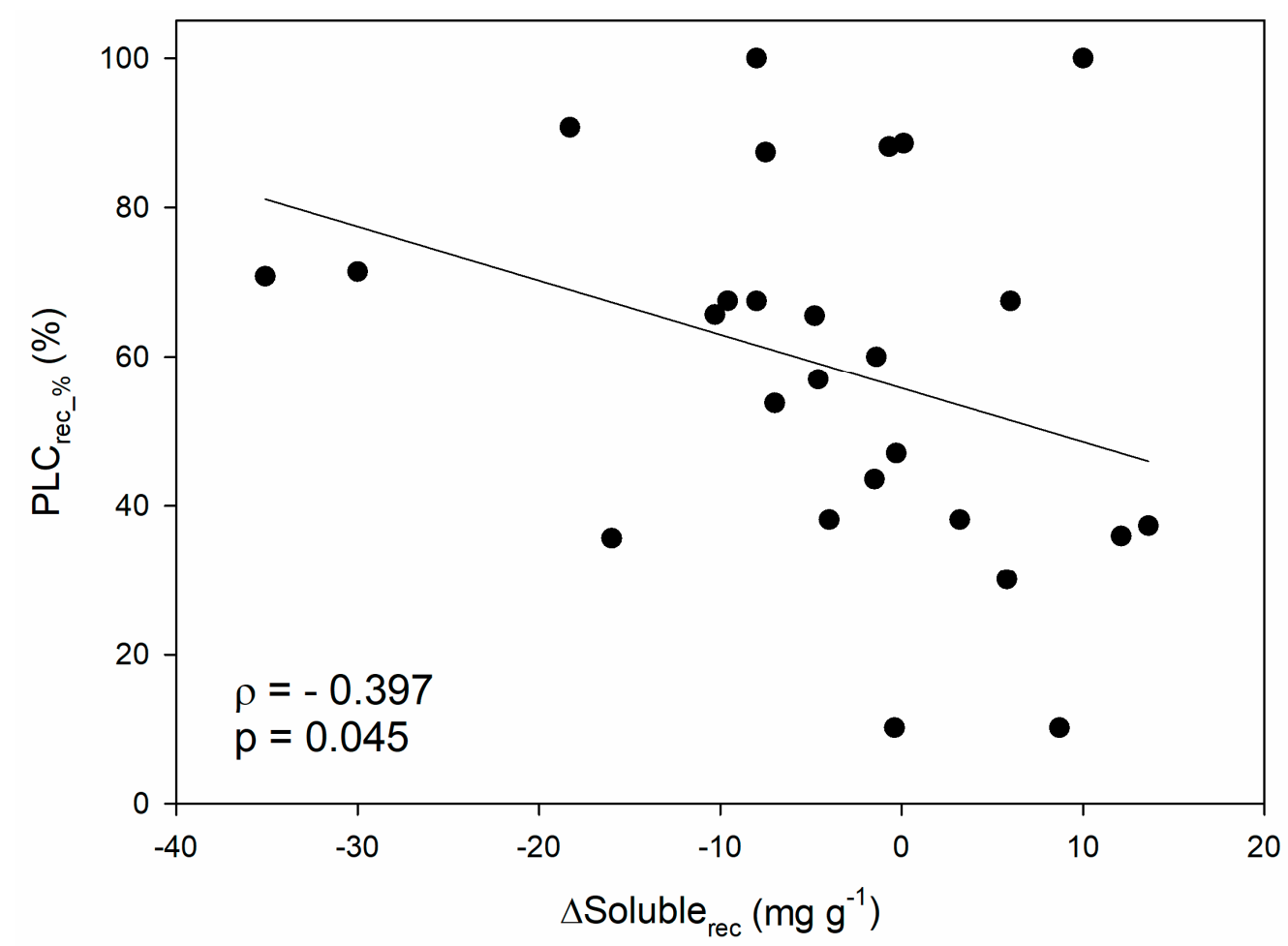

Figure 3. Relationship between percentage of recovered PLC (PLC rec_$\left.\%_{\%}\right)$ and the difference in soluble sugar content between recovery and end-drought/frost phase $\left(\Delta\right.$ Soluble $\left._{\text {rec }}\right)$. Spearman's correlation coefficient $(\rho)$, related $p$-value and regression line are reported.

In our survey we could not identify any relationship between hydraulic parameters and total NSCs or starch contents in the recovery phase. The stored starch content pools in stems are strictly dependent on the species-specific stem anatomical features such as wood parenchyma fraction [120], phenology, period of the year, length of the stress and in general by the environmental stress conditions previously faced by the plant $[118,125]$. Moreover, in some species lipids are accumulated instead of starch $[9,124]$. Variability in starch dynamics in relation to hydraulic dynamics can be exemplified by a few examples collected from the studies included in the data survey. In apple trees, xylem embolism that accumulated in autumn-winter months was later repaired in spring, and this was accompanied by starch depletion in the stems [122]. However, in P. abies and P. mugo hydraulic recovery in late winter via needle/branch water uptake was observed in combination with an increase in starch content in the phloem, whereas in summer the recovery of embolism formed in May in P. abies was accompanied by a decrease in starch content $[53,124]$. In potted saplings of the same species subjected to drought in a greenhouse, hydraulic recovery was accompanied by starch increase in bark but not in wood [8]. It must be, however, underlined that the available data are extremely heterogeneous in terms of tissue analyzed, drivers of embolism formation (winter-induced, summer drought, bench dehydration), length of stress and, especially, recovery period (see Table 1). NSC responses observed at recovery are likely to depend on the time interval between the occurrence of the rain event after drought and the timing of sample collection. This is justified by the fact that short-term and long-term NSC dynamics are different, and may depend on the speed at which drought stress relief occurs, that in turn influences NSC-affecting processes such as stomata reopening, photosynthesis and phloem transport restoration (see Figure 1b). 


\section{Conclusions and Future Perspectives}

Although several studies have underlined the importance of NSCs for maintaining hydraulic integrity under fluctuating water availability, a complete mechanistic picture of the processes involved is still lacking. In the light of the putative mechanisms of hydraulic regulation summarized in this review, we recognize the urgent need to design experiments in both controlled and field conditions that include the analysis of xylem sap, wood and bark NSC separately, and that in parallel quantify embolism during both drought and drought relief. In controlled greenhouse experiments, a possible approach that could shed light on role of NSCs in the plant hydraulic regulation is the manipulation of available NSCs in stems/roots, by coupling prolonged drought with, e.g., shading $[53,60,119]$ and by looking at the effect of NSC variations in the different stem compartments (xylem sap, bark, wood) on plant hydraulics. An important issue is the general lack of field experiments on PLC and NSC patterns during drought and recovery periods. In the light of the current trends of climate change-driven forest decline observed in several ecosystems, there is an urgent need to understand the effects of repeated droughts accompanied by heat waves on tree hydraulic and NSC deterioration.

Considering that model species have been mainly used to study the mechanisms involved, it is still unclear to which extent results hold true for other species. Indeed, the current model of embolism refilling has been extensively tested only in some species of the genus Populus (see [42] for details), but it should be validated in a broader range of species. Routinely adding NSC measurements to hydraulic measurements, by using standardized protocols for NSC sampling and analysis [126], could shed light onto possible connections between the hydraulic and carbohydrate components. Moreover, given the possible diel variations in NSC contents in different organs and positions in the trees [127], the sampling time for NSC analysis is also crucial for comparisons between studies. A timely monitoring of sugars in sap, together with NSCs in wood and bark, coupled with hydraulic measurements, is needed in order to elucidate whether possible common patterns exist across species.

As underlined in the previous section, it is clear how technically difficult is to relate environmentdriven NSC dynamics to the plant water status. Changes in solutes concentration during drought and recovery are likely to occur over small spatial and temporal scales [42]. Therefore, the gaps in knowledge on NSC dynamics in plants could be filled in the future by technological advances, including micro-scale localization of starch and sugar dynamics in parenchyma cells and non-functional xylem sap. A promising progress in this direction has been made by the use $\mathrm{X}$-ray micro-CT in combination with a machine-learning algorithm for in vivo quantification of starch dynamics in stems of grapevine [128].

A further challenge would be to understand if sugars and other organic compounds in xylem sap could play a role in preserving the hydraulic integrity during fluctuations in water availability and, generally, under environmental stress conditions.

Supplementary Materials: Supplementary materials can be found at http://www.mdpi.com/1422-0067/21/1/144/s1.

Author Contributions: Conceptualization, A.N., M.T. and V.C.; methodology, M.T.; statistical analysis, F.P. and M.T.; data curation and figure editing, M.T.; writing-original draft preparation, M.T.; writing-review and editing, M.T., A.N., V.C., E.P., F.P. All authors have read and agreed to the published version of the manuscript.

Conflicts of Interest: The authors declare no conflict of interest.

\section{Abbreviations}

PLC Percentage loss of hydraulic conductance

NSC Non-Structural Carbohydrates 


\section{Appendix A}

Table A1. Pearson's/Spearman's correlation coefficients between hydraulic and non-structural carbohydrate parameters during drought/winter stress.

\begin{tabular}{|c|c|c|c|c|c|c|c|c|c|}
\hline & Soluble end $_{\text {en }}$ & Starch $_{\text {end }}$ & TotNSC $_{\text {end }}$ & $\Delta$ Soluble $_{\text {end }}$ & $\Delta$ Starch $_{\text {end }}$ & $\Delta$ TotNSC $_{\text {end }}$ & Soluble $_{\text {end }} /$ Soluble $_{c}$ & Starch $_{\text {end }} /$ Starch $_{\mathrm{c}}$ & TotNSC $_{\text {end }} /$ TotNSCc \\
\hline$\Delta \mathrm{PLC}_{\mathrm{end}}$ & -0.273 & -0.196 & -0.324 & $-0.718^{* *}$ & -0.288 & 0.417 & $-0.592 *$ & 0.270 & $-0.707^{* *}$ \\
\hline $\mathrm{PLC}_{\text {end }}$ & 0.167 & 0.216 & 0.088 & 0 & $-0.708^{* *}$ & -0.551 * & -0.048 & -0.142 & $-0.473^{(*)}$ \\
\hline PLC $_{\text {rec_\% }} \%$ & I & I & I & $-0.555^{*}$ & 0.409 & 0.254 & -0.306 & -0.348 & 0.086 \\
\hline
\end{tabular}

Table A2. Pearson's/Spearman's correlation coefficients between hydraulic and non-structural carbohydrate parameters at recovery.

\begin{tabular}{|c|c|c|c|c|c|c|c|c|c|c|c|c|}
\hline & Soluble $_{\text {end }}$ & Starch $_{\text {end }}$ & TotNSC $_{\text {end }}$ & $\Delta$ Soluble $_{\text {rec }}$ & $\Delta$ Starch $_{\text {rec }}$ & $\Delta$ TotNSC $_{\text {rec }}$ & Soluble $_{\text {rec }}$ & Starch $_{\text {rec }}$ & Tot $_{\text {rec }}$ & Soluble $_{\text {rec }} /$ Soluble end $_{\text {en }}$ & Starch $_{\text {rec }} /$ Starch $_{\text {end }}$ & TotNSC $_{\text {rec }} /$ TotNSC $_{\text {end }}$ \\
\hline$\Delta \mathrm{PLC}_{\mathrm{rec}}$ & 0.027 & 0.067 & 0.160 & -0.287 & -0.172 & 0 & -0.067 & -0.009 & 0.297 & -0.201 & 0.160 & 0.276 \\
\hline $\mathrm{PLC}_{\text {rec_}} \%$ & 0.054 & $-0.284^{(*)}$ & -0.062 & $-0.397^{*}$ & -0.131 & -0.065 & -0.170 & $-0.324^{(*)}$ & -0.026 & -0.181 & 0.249 & -0.034 \\
\hline
\end{tabular}

Significance of correlations $(p<0.05)$ is indicated in bold. ${ }^{(*)} 0.05<p<0.10 ;{ }^{*} 0.01<p<0.05$. 


\section{References}

1. Raven, J.A. Selection pressures on stomatal evolution. New Phytol. 2002, 153, 371-386. [CrossRef]

2. Dai, A. Drought under global warming: A review. Wiley Interdiscip. Rev. Clim. Chang. 2011, 2, 45-65. [CrossRef]

3. Adams, H.D.; Zeppel, M.J.B.; Anderegg, W.R.L.; Hartmann, H.; Landhausser, S.M.; Tissue, D.T.; Huxman, T.E.; Hudson, P.J.; Franz, T.E.; Allen, C.D.; et al. A multi-species synthesis of physiological mechanisms in drought-induced tree mortality. Nat. Ecol. Evol. 2017, 1, 1285-1291. [CrossRef] [PubMed]

4. Choat, B.; Jansen, S.; Brodribb, T.J.; Cochard, H.; Delzon, S.; Bhaskar, R.; Bucci, S.J.; Field, T.S.; Gleason, S.M.; Hacke, U.G.; et al. Global convergence in the vulnerability of forests to drought. Nature 2012, 491, 752-755. [CrossRef] [PubMed]

5. Rowland, L.; Da Costa, A.C.L.; Galbraith, D.R.; Oliveira, R.S.; Binks, O.J.; Oliveira, A.A.R.; Pullen, A.M.; Doughty, C.E.; Metcalfe, D.B.; Vasconcelos, S.S.; et al. Death from drought in tropical forests in triggered by hydraulics not carbon starvation. Nature 2015, 528, 119-122. [CrossRef]

6. Hartmann, H.; Trumbore, S. Understanding the roles of non-structural carbohydrates in forest trees-From what we can measure to what we want to know. New Phytol. 2016, 211, 386-403. [CrossRef]

7. Deslauriers, A.; Beaulieu, M.; Balducci, L.; Giovannelli, A.; Gagnon, M.J.; Rossi, S. Impact of warming and drought on carbon balance related to wood formation in black spruce. Ann. Bot. 2014, 114, 335-345. [CrossRef]

8. Tomasella, M.; Häberle, K.-H.; Nardini, A.; Hesse, B.; Machlet, A.; Matyssek, R. Post-drought hydraulic recovery is accompanied by non-structural carbohydrate depletion in the stem wood of Norway spruce saplings. Sci. Rep. 2017, 7, 14308. [CrossRef]

9. Hoch, G.; Richter, A.; Körner, C. Non-structural carbon compounds in temperate forest trees. Plant Cell Environ. 2003, 26, 1067-1081. [CrossRef]

10. Lloret, F.; Sapes, G.; Rosas, T.; Galieno, L.; Saura-Mas, S.; Sala, A.; Martínez-Vilalta, J. Non-structural carbohydrate dynamics associated with drought-induced die-off in woody species of a shrubland community. Ann. Bot. 2018, 121, 1383-1396. [CrossRef]

11. McDowell, N.G.; Beerling, D.J.; Breshears, D.D.; Fisher, R.A.; Raffa, K.F.; Stitt, M. The interdependence of mechanisms underlying climate-driven vegetation mortality. Trends Ecol. Evol. 2011, 26, 523-532. [CrossRef] [PubMed]

12. Sevanto, S. Phloem transport and drought. J. Exp. Bot. 2014, 65, 1751-1759. [CrossRef] [PubMed]

13. Sevanto, S.; McDowell, N.G.; Dickman, I.T.; Pangle, R.; Pockman, W.T. How do trees die? A test of the hydraulic failure and carbon starvation hypotheses. Plant Cell Environ. 2014, 37, 153-161. [CrossRef] [PubMed]

14. Klein, T.; Zeppel, M.J.B.; Anderegg, W.R.L.; Bloemen, J.; De Kauwe, M.G.; Hudson, P.; Ruehr, N.K.; Powell, T.L.; Von Arx, G.; Nardini, A. Xylem embolism refilling and resilience against drought-induced mortality in woody plants: Processes and trade-offs. Ecol. Res. 2018, 33, 839-855. [CrossRef]

15. Brodribb, T.J.; Bowman, D.J.M.S.; Nichols, S.; Delzon, S.; Burlett, R. Xylem function and growth rate interact to determine recovery rates after exposure to extreme water deficit. New Phytol. 2010, 188, 533-542. [CrossRef]

16. Anderegg, W.R.L.; Schwalm, C.; Biondi, F.; Camarero, J.J.; Koch, G.; Litvak, M.; Ogle, K.; Shaw, J.D.; Shevliakova, E.; Williams, A.P.; et al. Pervasive drought legacies in forest ecosystems and their implications for carbon cycle models. Science 2015, 349, 528-532. [CrossRef]

17. Huntingford, C.; Atkin, O.K.; Martinez-de la Torre, A.; Mercado, L.M.; Heskel, M.A.; Harper, A.B.; Bloomfield, K.J.; O'Sullivan, O.S.; Reich, P.B.; Wythers, K.R.; et al. Implications of improved representations of plant respiration in a changing climate. Nat. Commun. 2017, 8, 1602. [CrossRef]

18. Tomasella, M.; Nardini, A.; Hesse, B.D.; Machlet, A.; Matyssek, R.; Häberle, K.-H. Close to the edge: Effects of repeated severe drought on stem hydraulics and non-structural carbohydrates in European beech saplings. Tree Physiol. 2019, 39, 717-728. [CrossRef]

19. Secchi, F.; Zwieniecki, M.A. Sensing embolism in xylem vessels: The role of sucrose as a trigger for refilling. Plant Cell Environ. 2011, 34, 514-524. [CrossRef]

20. Nardini, A.; Savi, T.; Trifilò, P.; Lo Gullo, M.A. Drought stress and the recovery from xylem embolism in woody plants. In Progress in Botany; Cánovas, F.M., Luettge, U., Matyssek, R., Eds.; Springer: Berlin, Germany, 2018; Volume 79, pp. 137-231.

21. McDowell, N.G.; Nardini, A.; Brodribb, T.J. Hydraulics in the 21st century. New Phytol. 2019, 224, 537-542. [CrossRef] 
22. Tyree, M.T.; Zimmermann, M.H. Xylem Structure and the Ascent of Sap, 2nd ed.; Springer: Berlin/Heidelberg, Germany, 2002.

23. Dixon, H.H.; Joly, J. On the ascent of sap. Ann. Bot. 1894, 8, 468-470. [CrossRef]

24. Tyree, M.T. Plant hydraulics: The ascent of water. Nature 2003, 423, 923. [CrossRef] [PubMed]

25. Hacke, U.G.; Sperry, J.S.; Pockman, W.T.; Davis, S.D.; McCulloh, K.A. Trends in wood density and structure are linked to prevention of xylem implosion by negative pressure. Oecologia 2001, 126, 457-461. [CrossRef]

26. Choat, B.; Cobb, A.R.; Jansen, S. Structure and function of bordered pits: New discoveries and impacts on whole-plant hydraulic function. New Phytol. 2008, 177, 608-626. [CrossRef] [PubMed]

27. Tyree, M.T.; Sperry, J.S. Vulnerability of xylem to cavitation and embolism. Annu. Rev. Plant Physiol. 1989, 40, 19-38. [CrossRef]

28. Vargaftik, N.B.; Volkov, B.N.; Voljak, L.D. International tables of the surface tension of water. J. Phys. Chem. Ref. Data 1983, 12, 817-820. [CrossRef]

29. Mayr, S.; Améglio, T. Freezing stress in tree xylem. Prog. Bot. 2016, 77, 381-414.

30. Sperry, J.S.; Hacke, U.G.; Pittermann, J. Size and function in conifer tracheids and angiosperm vessels. Am. J. Bot. 2006, 93, 1490-1500. [CrossRef]

31. Sperry, J.S.; Hacke, U.G.; Feild, T.S.; Sano, Y.; Sikkema, E.H. Hydraulic consequences of vessel evolution in angiosperms. Int. J. Plant Sci. 2007, 168, 1127-1139. [CrossRef]

32. Islam, M.; Rahman, M.; Bräuning, A. Long-term wood anatomical time series of two ecologically contrasting tropical tree species reveal differential hydraulic adjustment to climatic stress. Agric. For. Meteorol. 2019, 265, 412-423. [CrossRef]

33. Hillabrand, R.M.; Hacke, U.G.; Lieffers, V.J. Drought-induced xylem pit membrane damage in aspen and balsam poplar. Plant Cell Environ. 2016, 39, 2210-2220. [CrossRef] [PubMed]

34. Nardini, A.; Salleo, S.; Jansen, S. More than just a vulnerable pipeline: Xylem physiology in the light of ion-mediated regulation of plant water transport. J. Exp. Bot. 2011, 63, 4701-4718. [CrossRef] [PubMed]

35. Spicer, R. Symplasmic networks in secondary vascular tissues: Parenchyma distribution and activity supporting long-distance transport. J. Exp. Bot. 2014, 65, 1829-1848. [CrossRef] [PubMed]

36. Kedrov, G.B. Functioning wood. Wulfenia 2002, 19, 57-95.

37. Höll, W. Distribution, fluctuation and metabolism of food reserves in the wood of trees. In Cell and Molecular Biology of Wood Formation; Savidge, R., Barnett, J., Napier, R., Eds.; BIOS Scientific Publishers: Oxford, MS, USA, 2000; pp. 347-362.

38. Plavcová, L.; Hoch, G.; Morris, H.; Ghiasi, S.; Jansen, S. The amount of parenchyma and living fibers affects storage of nonstructural carbohydrates in young stems and roots of temperate trees. Am. J. Bot. 2016, 103, 603-612. [CrossRef]

39. Sauter, J.J.; Iten, W.I.; Zimmermann, M.H. Studies on the release of sugar into the vessels of the sugar maple (Acer saccharum). Can. J. Bot. 1973, 51, 1-8. [CrossRef]

40. Brodersen, C.R.; McElrone, A.J.; Choat, B.; Matthews, M.A.; Shackel, K.A. The dynamics of embolism repair in xylem: In vivo visualizations using high-resolution computed tomography. Plant Physiol. 2010, 154, 1088-1095. [CrossRef]

41. Salleo, S.; Lo Gullo, M.A.; Trifilò, P.; Nardini, A. New evidence for a role of vessel-associated cells and phloem in the rapid xylem refilling of cavitated stems of Laurus nobilis L. Plant Cell Environ. 2004, 27, 1065-1076. [CrossRef]

42. Secchi, F.; Pagliarani, C.; Zwieniecki, M.A. The functional role of xylem parenchyma cells and aquaporins during recovery from severe water stress. Plant Cell Environ. 2017, 40, 858-871. [CrossRef]

43. Meinzer, F.C.; James, S.A.; Goldstein, G.; Woodruff, D. Whole-tree water transport scales with sapwood capacitance on tropical forest canopy trees. Plant Cell Environ. 2017, 26, 1147-1155. [CrossRef]

44. Sakr, S.; Alves, G.; Morillon, R.; Maurel, K.; Decourteix, M.; Guilliot, A.; Fleurat-Lessard, P.; Julien, J.-L.; Chrispeels, M.J. Plasma membrane aquaporins are involved in winter embolism recovery in walnut tree. Plant Physiol. 2003, 133, 630-641. [CrossRef] [PubMed]

45. Rioux, D.; Nicole, M.; Simard, M.; Ouellette, G.B. Immunocytochemical evidence that secretion of pectin occurs during gel (gum) and tylosis formation in trees. Phytopathology 1998, 88, 494-505. [CrossRef] [PubMed]

46. De Boer, A.H.; Volkov, V. Logistics of water and salt transport through the plant: Structure and functioning of the xylem. Plant Cell Environ. 2003, 265, 87-101. [CrossRef] 
47. Morris, H.; Plavcova, L.; Goral, M.; Klepsch, M.M.; Kotowska, M.; Schenk, H.J.; Jansen, S. Vessel-associated cells in angiosperm xylem: Highly specialized living cells at the symplast-apoplast boundary. Am. J. Bot. 2018, 105, 1-10. [CrossRef] [PubMed]

48. Améglio, T.; Devourteix, M.; Alves, G.; Valentin, V.; Sakr, S.; Julien, J.L.; Pétel, G.; Guilliot, A.; Lacointe, A. Temperature effects on xylem sap osmolarity in walnut trees: Evidence for a vitalistic model of winter embolism repair. Tree Physiol. 2004, 24, 785-793. [CrossRef] [PubMed]

49. Wang, A.-Y.; Han, S.-J.; Zhang, J.-H.; Wang, M.; Yin, X.-H.; Fang, L.-D.; Yang, D.; Hao, G.-Y. The interaction between nonstructural carbohydrate reserves and xylem hydraulics in Korean pine trees across an altitudinal gradient. Tree Physiol. 2018, 38, 1792-1804. [CrossRef]

50. Mayr, S.; Schmid, P.; Laur, J.; Rosner, S.; Charra-Vaskou, K.; Damon, B.; Hacke, U.G. Uptake of water via branches helps timberline conifers refill embolized xylem in late winter. Plant Physiol. 2014, 164, 1731-1740. [CrossRef]

51. Lintunen, A.; Mayr, S.; Salmon, Y.; Cochard, H.; Höltta, T. Drivers of apoplastic freezing in gymnosperm and angiosperm branches. Ecol. Evol. 2018, 8, 333-343. [CrossRef]

52. Chen, T.H.; Murata, N. Enhancement of tolerance of abiotic stresses by metabolic engineering of betaines and other compatible solutes. Curr. Opin. Plant Biol. 2002, 5, 250-257. [CrossRef]

53. O’Brien, M.J.; Leuzinger, S.; Philipson, C.D.; Hector, T.J. Drought survival of tropical tree seedlings enhanced by non-structural carbohydrate levels. Nat. Clim. Chang. 2014, 4, 710-714. [CrossRef]

54. Sala, A.; Woodruff, D.R.; Meinzer, F.C. Carbon dynamics in tree: Feast or famine? Tree Phyisol. 2012, 32, 764-775. [CrossRef] [PubMed]

55. Wittmann, C.; Pfanz, H. Antitranspirant functions of stem periderms and their influence on corticular photosynthesis under drought stress. Trees 2008, 22, 187-196. [CrossRef]

56. Vandegehuchte, M.M.; Bloemen, J.; Vergeynst, L.L.; Steppe, K. Woody tissue photosynthesis in trees: Salve on the wounds of drought? New Phytol. 2015, 208, 998-1002. [CrossRef] [PubMed]

57. Eyles, A.; Pinkard, E.A.; O'Grady, A.P.; Worledge, D.; Warren, C.R. Role of corticular photosynthesis following defoliation in Eucaliptus globulus. Plant Cell Environ. 2009, 32, 1004-1014. [CrossRef] [PubMed]

58. Schmitz, N.; Egerton, J.J.G.; Lovelock, C.E.; Ball, M.C. Light-dependent maintenance of hydraulic function in mangrove branches: Do xylary chloroplasts play a role in embolism repair? New Phytol. 2012, 195, 40-46. [CrossRef] [PubMed]

59. Bloemen, J.; Vergeynst, L.L.; Overlaet-Michelis, L.; Steppe, K. How important is woody tissue photosynthesis in poplar during drought stress? Trees 2016, 30, 63-72. [CrossRef]

60. De Baerdemaeker, N.J.F.; Salomon, R.L.; De Roo, L.; Steppe, K. Sugars from woody tissue photosynthesis reduce vulnerability to cavitation. New Phytol. 2017, 216, 720-727. [CrossRef]

61. Schenk, H.J.; Steppe, K.; Jansen, S. Nanobubbles: A new paradigm for air-seeding in xylem. Trends Plant Sci. 2015, 20, 199-205. [CrossRef]

62. Schenk, H.J.; Espino, S.; Romo, D.M.; Nima, N.; Do, A.Y.T.; Michaud, J.M.; Papahadjopoulos-Sternberg, B.; Yang, J.; Zuo, Y.Y.; Steppe, K.; et al. Xylem surfactants introduce a new element to the cohesion-tension theory. Plant Physiol. 2017, 173, 1177-1196. [CrossRef]

63. Secchi, F.; Zwieniecki, M.A. Down-regulation of plasma intrinsic protein1 aquaporin in poplar trees is detrimental to recovery from embolism. Plant Physiol. 2014, 164, 1789-1799. [CrossRef]

64. Pagliarani, C.; Casolo, V.; Beiragi, M.A.; Cavalletto, S.; Siciliano, I.; Schubert, A.; Gullino, M.L.; Zwieniecki, M.A.; Secchi, F. Priming xylem for stress recovery depends on coordinated activity of sugar metabolic pathways and changes in xylem sap pH. Plant Cell Environ. 2019, 42, 1775-1787. [CrossRef]

65. Nardini, A.; Lo Gullo, M.A.; Salleo, S. Refilling of embolized conduits: Is it a matter of phloem unloading? Plant Sci. 2011, 180, 604-611. [CrossRef] [PubMed]

66. Bucci, S.J.; Scholz, F.G.; Goldstein, G.; Meinzer, F.C.; Sternberg, L.D.L. Dynamic changes in hydraulic conductivity in petioles of two savanna tree species: Factors and mechanisms contributing to the refilling of embolized vessels. Plant Cell Environ. 2003, 26, 1633-1645. [CrossRef]

67. Salleo, S.; Trifilò, P.; Esposito, S.; Nardini, A.; Lo Gullo, M.A. Starch-to-sugar conversion in wood parenchyma of field-growing laurus nobilis plants: A component if the signal pathway for embolims repair? Funct. Plant Biol. 2009, 36, 815-825. [CrossRef]

68. Secchi, F.; Zwieniecki, M.A. Analysis of xylem sap from functional (nonembolized) and non-functional (embolized) vessels of Populus nigra: Chemistry of refilling. Plant Physiol. 2012, 160, 955-964. [CrossRef] 
69. Sharp, R.G.; Davies, W.J. Variability among species in the apoplastic pH signalling response to drying soils. J. Exp. Bot. 2009, 60, 4363-4370. [CrossRef] [PubMed]

70. Losso, A.; Beikircher, B.; Dämon, B.; Kikuta, S.; Schmid, P.; Mayr, S. Xylem sap surface tension may be crucial for hydraulic safety. Plant Physiol. 2017, 175, 1135-1143. [CrossRef] [PubMed]

71. Secchi, F.; Zwieniecki, M.A. Accumulation of sugars in the xylem apoplast observed under water stress conditions is controlled by xylem pH. Plant Cell Environ. 2016, 39, 2350-2360. [CrossRef]

72. Secchi, F.; Gilbert, M.E.; Zwieniecki, M.A. Transcriptome response to embolism formation in stems of Populus trichocarpa provides insight into signaling and the biology of refilling. Plant Physiol. 2011, 157, 1419-1429. [CrossRef]

73. Perrone, I.; Pagliarani, C.; Lovisolo, C.; Chitarra, W.; Roman, F.; Schubert, A. Recovery from water stress affects grape leaf petiole transcriptome. Planta 2012, 235, 1383-1396. [CrossRef]

74. Secchi, F.; Zwieniecki, M.A. Patterns in PIP gene expression in Populus trichocarpa during recovery from xylem embolism suggest a major role for the PIP1 aquaporin subfamily as moderators of refilling process. Plant Cell Environ. 2010, 33, 1285-1297. [CrossRef] [PubMed]

75. Chitarra, W.; Balestrini, R.; Vitali, M.; Pagliarani, C.; Perrone, I.; Schubert, A. Gene expression in vessel-associated cells upon xylem embolism repair in Vitis vinifera L. Planta 2014, 239, 887-899. [CrossRef] [PubMed]

76. Kempa, S.; Krasensky, J.; Dal Santo, S.; Kopka, J.; Jonak, C. A central role of abscisic acid in stress-regulated carbohydrate metabolism. PLoS ONE 2008, 3, e3935. [CrossRef] [PubMed]

77. Brunetti, C.; Gori, A.; Marino, G.; Latini, P.; Sobolev, A.P.; Nardini, A.; Haworth, M.; Giovannelli, A.; Capitani, D.; Loreto, F.; et al. Dynamic changes in ABA content in water-stressed Populus nigra: Effects of carbon fixation and soluble carbohydrates. Ann. Bot. 2019. [CrossRef] [PubMed]

78. Cochard, H.; Lemoine, D.; Ameglio, T.; Granier, A. Mechanisms of xylem recovery from winter embolism in Fagus sylvatica. Tree Physiol. 2001, 21, 27-33. [CrossRef] [PubMed]

79. Roach, M.; Arrivault, S.; Mahboubi, A.; Krohn, N.; Sulpice, R.; Stitt, M.; Niittylä, T. Spatially resolved metabolic analysis reveals a central role for transcriptional control in carbon allocation to wood. J. Exp. Bot. 2017, 68, 3529-3539. [CrossRef]

80. Mahboubi, A.; Niittylä, T. Sucrose transport and carbon fluxes during wood formation. Physiol. Plant. 2018, 164, 67-81. [CrossRef]

81. Hacke, U.G.; Sauter, J.J. Xylem dysfunction during winter and recovery of hydraulic conductivity in diffuse-porous and ring-porous trees. Oecologia 1996, 105, 435-439. [CrossRef]

82. Yang, S.J.; Zhang, Y.J.; Sun, M.; Goldstein, G.; Cao, K.F. Recovery of diurnal depression of leaf hydraulic conductance in a subtropical woody bamboo species: Embolism refilling by nocturnal root pressure. Tree Physiol. 2012, 32, 414-422. [CrossRef]

83. Ewers, F.W.; Ameglio, F.W.; Cochard, H.; Beaujard, F.; Martignac, M.; Vandame, M.; Bodet, C.; Cruiziat, P. Seasonal variation in xylem pressure of walnut trees: Root and stem pressures. Tree Physiol. 2001, 21, 1123-1132. [CrossRef]

84. Améglio, T.; Bodet, C.; Lacointe, A.; Cochard, H. Winter embolism, mechanisms of xylem hydraulic conductivity recovery and springtime growth patterns in walnut and peach trees. Tree Physiol. 2002, 22, 1211-1220. [CrossRef] [PubMed]

85. Brodersen, C.R.; McElrone, A.J. Maintenance of xylem network transport capacity: A review of embolism repair in vascular plants. Front. Plant Sci. 2013, 4, 108. [CrossRef] [PubMed]

86. Hao, G.Y.; Wheeler, J.K.; Holbrook, N.M.; Goldstein, G. Investigating xylem embolism formation, refilling and water storage in tree trunks using frequency domain reflectometry. J. Exp. Bot. 2013, 64, 2321-2332. [CrossRef] [PubMed]

87. Westhoff, M.; Schneider, H.; Zimmermann, D.; Mimietz, S.; Stinzing, A.; Wegner, L.; Kaiser, W.; Krohne, G.; Shirley, S.; Jakob, P.; et al. The mechanisms of refilling of xylem conduits and bleeding of tall birch during spring. Plant Biol. 2008, 10, 604-623. [CrossRef]

88. Améglio, T.; Ewers, F.W.; Cochard, H.; Martignac, M.; Vandame, M.; Bodet, C.; Cruiziat, P. Winter stem pressures in walnut trees: Effects of carbohydrates, cooling and freezing. Tree Physiol. 2001, 21, 387-394. [CrossRef]

89. Brodersen, C.R.; Knipfer, T.; McElrone, A.J. In vivo visualization of the final stages of xylem vessel refilling in grapevine (Vitis vinifera) stems. New Phytol. 2018, 217, 117-126. [CrossRef] 
90. Knipfer, T.; Cuneo, I.F.; Brodersen, C.R.; McElrone, A.J. In situ visualization of the dynamics in xylem embolism formation and removal in the absence of root pressure: A study on excised grapevine stems. Plant Physiol. 2016, 171, 1024-1036. [CrossRef]

91. Heizmann, U.; Kreuzwieser, J.; Schnitzler, J.P.N.; Bruggemann, N.; Rennenberg, H. Assimilate transport in the xylem sap of pedunculated oak (Quercus robur) saplings. Plant Biol. 2001, 3, 132-138. [CrossRef]

92. Fromard, L.; Babin, V.; Fleurat-Lessard, P.; Fromont, J.C.; Serrano, R.; Bonnemain, J.L. Control of vascular sap $\mathrm{pH}$ by the vessel-associated cells in woody species. Plant Physiol. 1995, 108, 913-918. [CrossRef]

93. Yoshimura, K.; Saiki, S.-T.; Yazaki, K.; Ogasa, M.Y.; Shirai, M.; Nakano, T.; Yoshimura, J.; Ishida, A. The dynamics of carbon stored in xylem sapwood to drought-induced hydraulic stress in mature trees. Sci. Rep. 2016, 6, 24513. [CrossRef]

94. Losso, A.; Nardini, A.; Dämon, B.; Mayr, S. Xylem sap chemistry: Seasonal changes in timberline conifers Pinus cembra, Picea abies, Larix decidua. Biol. Plant. 2018, 62, 157-165. [CrossRef]

95. Oroian, M.; Ropciuc, S.; Amariei, S.; Gutt, G. Correlations between density viscosity, surface tension and ultrasonic velocity of different mono- and di-saccharides. J. Mol. Liq. 2015, 207, 145-151. [CrossRef]

96. Beattie, J.K.; Djerdjev, A.M.; Gray-Weale, A.; Kallay, N.; Lützenkirchen, J.; Preočanin, T.; Selmani, A. pH and the surface tension of water. J. Colloid Interface Sci. 2014, 422, 54-57. [CrossRef] [PubMed]

97. Christensen-Dalsgaard, K.K.; Tyree, M.T.; Mussone, P.G. Surface tension phenomena in the xylem sap of three diffuse porous temperate tree species. Tree Physiol. 2011, 31, 361-368. [CrossRef]

98. Salleo, S.; Lo Gullo, M.A.; De Paoli, D.; Zippo, M. Xylem recovery from cavitation-induced embolism plants of Laurus nobilis: A possible mechanism. New Phytol. 1996, 132, 47-56. [CrossRef]

99. Zwieniecki, M.A.; Hutyra, L.; Thompson, M.V.; Holbrook, N.M. Dynamic changes in petiole specific conductivity in red maple (Acer rubrum L.), tulip tree (Liriodendron tulipifera L.) and northern fox grape (Vitis labrusca). Plant Cell Environ. 2000, 23, 407-414. [CrossRef]

100. Salleo, S.; Trifilo, P.; Lo Gullo, M.A. Phloem as a possible major determinant of rapid cavitation reversal in stems of Laurus nobilis (laurel). Funct. Plant Biol. 2006, 33, 1063-1074. [CrossRef]

101. Liu, J.; Gu, L.; Yu, Y.; Huang, P.; Wu, Z.; Zhang, Q.; Qian, Y.; Wan, X.; Sun, Z. Corticular photosynthesis drives bark water uptake to refill embolized vessels in dehydrated branches of Salix matsudana. Plant Cell Environ. 2019, 42, 2584-2596. [CrossRef]

102. Martorell, S.; Diaz-Espejo, A.; Medrano, H.; Ball, M.C.; Choat, B. Rapid hydraulic recovery of Eucalyptus pauciflora after drought: Link-ages between stem hydraulics and leaf gas exchange. Plant Cell Environ. 2014, 37, 617-626. [CrossRef]

103. Trifilò, P.; Casolo, V.; Raimondo, F.; Petrussa, E.; Boscutti, F.; Lo Gullo, M.A.; Nardini, A. Effects of prolonged drought on stem non-structural carbohydrates content and post-drought hydraulic recovery in Laurus noblis L.: The possible link between carbon starvation and hydraulic failure. Plant Physiol. Biochem. 2017, 120, $232-241$. [CrossRef]

104. Wheeler, J.K.; Huggert, B.A.; Tofte, A.N.; Rockwell, F.E.; Holbrook, N.M. Cutting xylem under tension or supersaturated with gas can generate PLC and the appearance of rapid recovery from embolism. Plant Cell Environ. 2013, 36, 1938-1949. [CrossRef] [PubMed]

105. Trifilò, P.; Raimondo, F.; Lo Gullo, M.A.; Barbera, P.M.; Salleo, S.; Nardini, A. Relax and refill: Xylem rehydration prior to hydraulic measurements favours embolism repair in stems and generates artificially low PLC values. Plant Cell Environ. 2014, 37, 2491-2499. [CrossRef] [PubMed]

106. Torres-Ruiz, J.M.; Jansen, S.; Choat, B.; McElrone, A.J.; Cochard, H.; Brodribb, T.J.; Badel, E.; Burlett, R.; Bouche, P.S.; Brodersen, C.R.; et al. Direct X-Ray microtomography observations confirm the induction of embolism upon xylem cutting under tension. Plant Physiol. 2015, 167, 40-43. [CrossRef]

107. Cochard, H.; Delzon, S. Hydraulic failure and repair are not routine in trees. Ann. For. Sci. 2013, 70, 659-661. [CrossRef]

108. Holbrook, N.M.; Ahrens, E.T.; Burns, M.J.; Zwieniecki, M.A. In vivo observation of cavitation and embolism repair using magnetic resonance imaging. Plant Physiol. 2001, 126, 27-31. [CrossRef] [PubMed]

109. Knipfer, T.; Eustis, A.; Brodersen, C.; Walker, A.M.; McElrone, A.J. Grapevine species from varied native habitats exhibit differences ibn embolism formation/repair associated with leaf gas exchange and root pressure. Plant Cell Environ. 2015, 38, 1503-1513. [CrossRef] [PubMed]

110. Zwieniecki, M.A.; Melcher, P.J.; Ahrens, E.T. Analysis of spatial and temporal dynamics of xylem refilling in Acer rubrum L. using magnetic resonance imaging. Front. Plant Sci. 2013, 4, 265. [CrossRef] [PubMed] 
111. Clearwater, M.J.; Clark, C.J. In vivo magnetic resonance imaging of xylem vessel contents in woody lianas. Plant Cell Environ. 2003, 26, 1205-1214. [CrossRef]

112. Charrier, G.; Torres-Ruiz, J.M.; Badel, E.; Burlett, R.; Choat, B.; Cochard, H.; Delmas, E.L.; Domec, J.-C.; Jansen, S.; King, A.; et al. Evidence for hydraulic vulnerability segmentation and lack of xylem refilling under tension. Plant Physiol. 2016, 172, 1657-1668. [CrossRef]

113. Choat, B.; Brodersen, C.R.; McElrone, A.J. Synchrotron X-ray microtomography of xylem embolism in Sequoia sempervirens saplings during cycles of drought and recovery. New Phytol. 2015, 205, 1095-1105. [CrossRef]

114. Petruzzellis, F.; Pagliarani, C.; Savi, T.; Losso, A.; Cavalletto, S.; Tromba, G.; Dullin, C.; Bär, A.; Ganthaler, A.; Miotto, A.; et al. The pitfalls of in vivo imaging techniques: Evidence for cellular damage caused by synchrotron X-ray computed micro-tomography. New Phytol. 2018, 220, 104-110. [CrossRef] [PubMed]

115. Laur, J.; Hacke, U. Exploring Picea glauca aquaporins in the context of needle water uptake and xylem refilling. New Phytol. 2014, 203, 388-400. [CrossRef] [PubMed]

116. Eller, C.B.; Lima, A.L.; Oliveira, R.S. Foliar uptake of fog water and transport belowground alleviates drought effects in the cloud forest tree species, Drimys brasiliensis (Winteraceae). New Phytol. 2003, 199, 151-162. [CrossRef] [PubMed]

117. Earles, J.M.; Sperling, O.; Silva, L.C.R.; Brodersen, C.R.; North, M.P.; Zwieniecki, M.A. Bark water uptake promotes localized hydraulic recovery in coastal redwood crown. Plant Cell Environ. 2016, 39, 320-328. [CrossRef]

118. Yu, Y.C.; Liu, J.X.; Sun, Z.Y. Transcriptome profiling in Salix matsudana during refilling xylem vessels after embolism. Biol. Plant. 2019, 63, 425-431. [CrossRef]

119. Tomasella, M.; Casolo, V.; Aichner, N.; Petruzzellis, F.; Savi, T.; Trifilò, P.; Nardini, A. Non-structural carbohydrate and hydraulic dynamics during drought and recovery in Fraxinus ornus and Ostrya carpinifolia saplings. Plant Physiol. Biochem. 2019, 145. [CrossRef]

120. Trifilò, P.; Kiorapostolou, N.; Petruzzellis, F.; Vitti, S.; Petit, G.; Lo Gullo, M.; Nardini, A.; Casolo, V. Hydraulic recovery from xylem embolism in excised branches of twelve woody species: Relationships with parenchyma cells and non-structural carbohydrates. Plant Physiol. Biochem. 2019, 139, 513-520. [CrossRef]

121. Savi, T.; Casolo, V.; Luglio, J.; Bertuzzi, S.; Trifilò, P.; Lo Gullo, M.A.; Nardini, A. Species-specific reversal of stem xylem embolism after a prolonged drought correlates to endpoint concentration of soluble sugars. Plant Physiol. Biochem. 2016, 106, 198-207. [CrossRef]

122. Beikircher, B.; Mittmann, C.; Mayr, S. Prolonged soil frost affects hydraulics and phenology of apple trees. Front. Plant Sci. 2016, 7, 867. [CrossRef]

123. Beikircher, B.; Mayr, S. Annual patterns of xylem embolism in high-yield apple cultivars. Funct. Plant Biol. 2017, 44, 587-596. [CrossRef]

124. Mayr, S.; Schmid, P.; Rosner, S. Winter embolism and recovery in the conifer schrub Pinus mugo L. Forests 2019, 10, 941. [CrossRef]

125. Tixier, A.; Gambetta, G.A.; Orozco, J.; Zwieniecki, M.A. Non-structural carbohydrates in dormant woody perennials; the tale of winter survival and spring arrival. Front. For. Glob. Chang. 2019, 2, 18. [CrossRef]

126. Landhausser, S.M.; Chow, P.S.; Dickman, L.T.; Furze, M.E.; Kuhlman, I.; Schmid, S.; Wiesbauer, J.; Wild, B.; Gleixner, G.; Hartmann, H.; et al. Standardized protocols and procedures can precisely and accurately quantify non-structural carbohydrates. Tree Physiol. 2018, 38, 1764-1778. [CrossRef] [PubMed]

127. Tixier, A.; Orozco, J.; Roxas, A.A.; Earles, J.M.; Zwieniecki, M.A. Diurnal variation in nonstructural carbohydrate storage in trees: Remobilization and vertical mixing. Plant Physiol. 2018, 178, 1602-1613. [CrossRef]

128. Earles, J.M.; Knipfer, T.; Tixier, A.; Orozco, J.; Reyes, C.; Zwieniecki, M.A.; Brodersen, C.R.; McElrone, A.J. In vivo quantification of plant starch reserves at micrometer resolution using $\mathrm{X}$-ray microCT imaging and machine learning. New Phytol. 2018, 218, 1260-1269. [CrossRef]

(C) 2019 by the authors. Licensee MDPI, Basel, Switzerland. This article is an open access article distributed under the terms and conditions of the Creative Commons Attribution (CC BY) license (http://creativecommons.org/licenses/by/4.0/). 